\title{
Microstructural Analysis of the Steels from Buildings 7, \& 1 or 2 from the World Trade Center
}

\author{
R. R. Biederman, ${ }^{*}$ Erin M. Sullivan, ${ }^{*}$ R. D. Sisson, Jr., ${ }^{*}$ and George F. Vander Voort** \\ *Materials Science \& Engineering Program, Mechanical Engineering Department, Worcester \\ Polytechnic Institute, Worcester, MA 01609-2280 \\ **Buehler, Ltd., 41 Waukegan Rd., Lake Bluff, IL 60044
}

Several samples from Buildings 7, and 1 or 2 of the World Trade Center were collected during the FEMA forensic investigation shortly after September 11, 2001. Macroscopically these samples revealed severe "erosion" of the steel beam thickness from $1 / 2$ inch to total metal loss in some regions, as well as localized plastic deformation. We were asked to determine the cause of this "erosion" as well the temperature that the steel experienced. Figure 1 shows typical examples of the severe erosion that occurred in the beam.

A microstructural analysis of these steel samples has been completed. In Building 7, the structural steel was A36. Figure 2 shows the near surface microstructural changes that occurred in the steel.

The as-fabricated microstructure consisted of a hot worked banded structure of ferrite and pearlite. In severely "eroded" regions where the thickness had been reduced to less than a 1/16 of and inch significant decarburization was observed. In addition, some pearlite bands presented regions that had re-austentized as well as regions where the pearlite had started to spheroidize. These observations indicate that steel had experienced temperature between 550 and $850^{\circ} \mathrm{C}$.

An examination of the "slag" that formed on the surface of the steel found iron oxides and iron sulfides. It appeared that the "slag" was liquid at high temperature and easily attacked the grain boundaries. A eutectic microstructure was seen within the "slag" of iron oxides and iron sulfides. If these compounds were pure wustite $(\mathrm{FeO})$ and iron sulfide $(\mathrm{FeS})$, the eutectic temperature is $940^{\circ} \mathrm{C}$. It appears that the severe "erosion" was due to the sulfidation and oxidation (i.e., hot corrosion) of the steel followed by the liquid "slag" attack of the grain boundaries.

A sample from either Building 1 or 2 presented similar macroscopic observations. In these buildings, the steel was a high strength low alloy steel (HSLA). The microstructure revealed somewhat different phase distributions. This steel contained less carbon and an alloy addition of copper. The "slag" while comprised of both iron oxides and iron sulfides presented a significantly different microstructure near the surface as shown in Figure 3.

Evidence of grain boundary attack by sulfidation is clearly visible. A gradient in sulfur concentration inward from the surface is shown in Figure 4. The internal sulfides appeared to interact with the penetration of this liquid "slag."

A thermodynamic analysis of the Fe-S-O system is currently underway to determine the atmosphere that would form these sulfidation/oxidation products. In addition, these microstructural observations will be compared with results from steels in various furnace and petrochemical processes. 


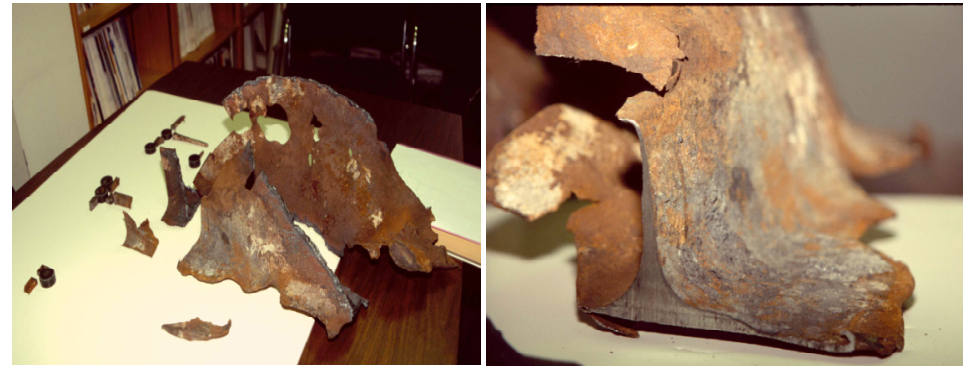

FIG. 1. Severely Eroded 1/2 inch wide flange beam from WTC 7.

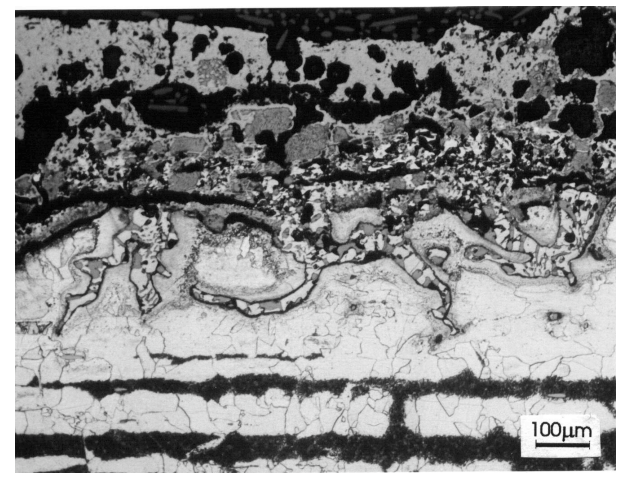

FIG. 2. Near surface oxidation and intergranular sulfidation.

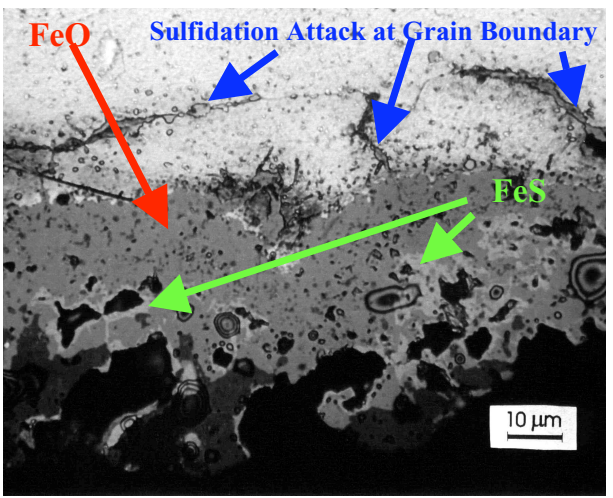

FIG. 3. Surface reaction region in WTC 1 or 2 column member.

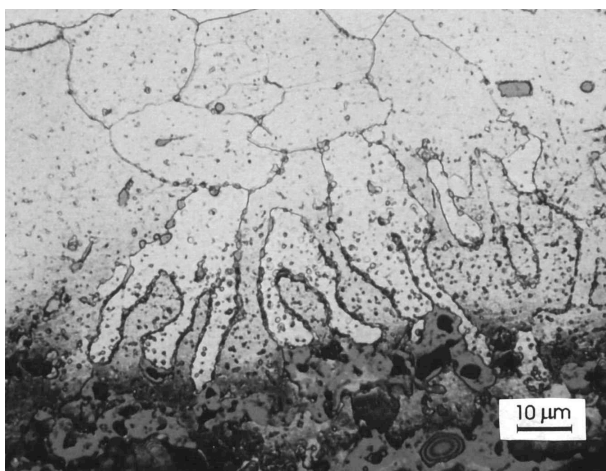

FIG. 4. Hot Corrosion in WTC 1 or 2 steel. 